\title{
The Effect of Uncinate Process Resection on Subsidence Following Anterior Cervical Discectomy and Fusion
}

\author{
Su Hun Lee, M.D., ${ }^{1,2,3}$ Jun Seok Lee, M.D., ${ }^{1,2,3}$ Soon Ki Sung, M.D., Ph.D., ${ }^{1,2,3}$ Dong Wuk Son, M.D., Ph.D., ${ }^{1,2,3}$ \\ Sang Weon Lee, M.D., Ph.D., ${ }^{1,2,3}$ Geun Sung Song, M.D., Ph.D., ${ }^{1,2,3}$ \\ Department of Neurosurgery, Pusan National University Yangsan Hospital, Yangsan, Korea \\ Research Institute for Convergence of Biomedical Science and Technology, ${ }^{2}$ Pusan National University Yangsan Hospital, Yangsan, Korea \\ Department of Neurosurgery, ${ }^{3}$ Pusan National University School of Medicine, Yangsan, Korea
}

Objective : Subsidence is a frequent complication of anterior cervical discectomy and fusion. Postoperative segmental micromotion, thought to be a causative factor of subsidence, has been speculated to increase with uncinate process resection area (UPR). To evaluate the effect of UPR on micro-motion, we designed a method to measure UPR area based on pre- and postoperative computed tomography images and analyzed the relationship between UPR and subsidence as a proxy of micro-motion.

Methods : We retrospectively collected clinical and radiological data from January 2011 to June 2016. A total of 38 patients (53 segments) were included. All procedures included bilateral UPR and anterior plate fixation. UPR area was evaluated with reformatted coronal computer tomography images. To reduce level-related bias, we converted UPR area to the proportion of UPR to the pre-operative UP area (pUPR).

Results : Subsidence occurred in 18 segments (34\%) and positively correlated with right-side pUPR, left-side pUPR, and the sum of bilateral pUPR (sum pUPR) $(R=0.310,301,364 ; p=0.024,0.029,0.007$, respectively). Multiple linear regression analysis revealed that subsidence could be estimated with the following formula : subsidence $=1.522+2.7 \times$ sum $p U P R\left(R^{2}=0.133, p=0.007\right)$. Receiveroperating characteristic analysis determined that sum $\mathrm{pUPR} \geq 0.38$ could serve as a threshold for significantly increased risk of subsidence $(p=0.005$, area under curve $=0.737$, sensitivity $=94 \%$, specificity $=51 \%)$. This threshold was confirmed by logistic regression analysis for subsidence $(p=0.009$, odds ratio $=8.471)$.

Conclusion : The UPR measurement method confirmed that UPR was correlated with subsidence. Particularly when the sum of pUPR is $\geq 38 \%$, the possibility of subsidence increased.

Key Words : Spondylosis · Prosthesis failure · Zygapophyseal joint · Spinal fusion · Complication.

\section{INTRODUCTION}

Uncinate process (UP) hypertrophy commonly accompanies degenerative cervical spondylosis and can cause radicu- lopathy by compressing the root of the neural foramen ${ }^{24)}$. In this event, direct decompression of the neural foramen by UP resection is preferable to indirect decompression by anterior cervical discectomy and fusion (ACDF). However, cervical in-

- Received : February 23, 2017 •Revised : April 7, 2017 • Accepted : April 19, 2017

- Address for reprints : Dong Wuk Son, M.D, Ph.D.

Department of Neurosurgery, Pusan National University Yangsan Hospital, 20 Geumo-ro, Mulgeum-eup, Yangsan 50612, Korea Tel : +82-55-360-2126, Fax : +82-55-360-2156, E-mail : md6576@naver.com

This is an Open Access article distributed under the terms of the Creative Commons Attribution Non-Commercial License (http://creativecommons.org/licenses/by-nc/4.0) which permits unrestricted non-commercial use, distribution, and reproduction in any medium, provided the original work is properly cited. 
stability after UP resection remains controversial.

Subsidence is a major complication of $\mathrm{ACDF}^{2}$. Various factors including cage type ${ }^{2,7,20)}$ and location ${ }^{18)}$, distractive force ${ }^{6)}$, end-plate preparation ${ }^{13)}$, and particularly, a small degree of segmental instability (micro-motion) ${ }^{9,17,26)}$ may affect subsidence.

The uncovertebral joints play roles in limiting both posterior translation and lateral flexion in the cervical spine ${ }^{25)}$ due to their anatomical characteristics. They comprise a process, corresponding recess, and surrounding ligament ${ }^{5}$. Resection of these structures might attenuate the limitation mechanism and cause cervical instability. Kotani et al. ${ }^{11)}$ demonstrated that even with a bone graft construct, increasing UP resection (UPR) area progressively decreased functional spinal unit stability. Furthermore, since anterior cervical discectomy and fusion (ACDF) with plating (ACDFP) is insufficient to support stability, graft engagement to the uncovertebral joint is important to provide a rigid environment for fusion ${ }^{28)}$.

To test the possibility that greater UPR promotes greater segmental instability, we devised a method to measure UPR and investigated its relationship with subsidence as a proxy of micro-motion.

\section{MATERIALS AND METHODS}

We hypothesized that the UPR is related with segmental instability, which leads to increased subsidence (Fig. 1).

\section{Patients}

Between January 2011 and June 2016, data from 190 patients who underwent ACDF for cervical spondylosis at a single institution were collected. The inclusion criteria were 1) ACDF performed by a single surgeon, 2) pre- and post- operative

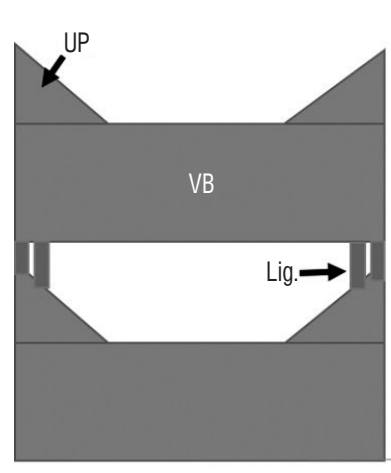

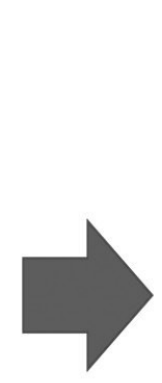

Distraction and cage insertion
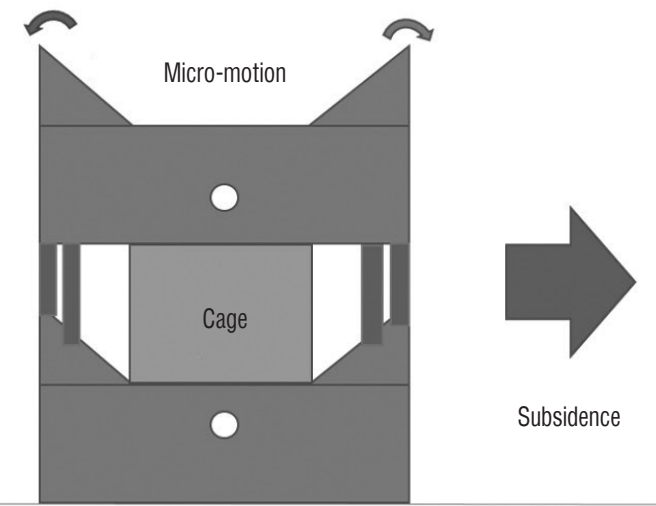

Subsidence
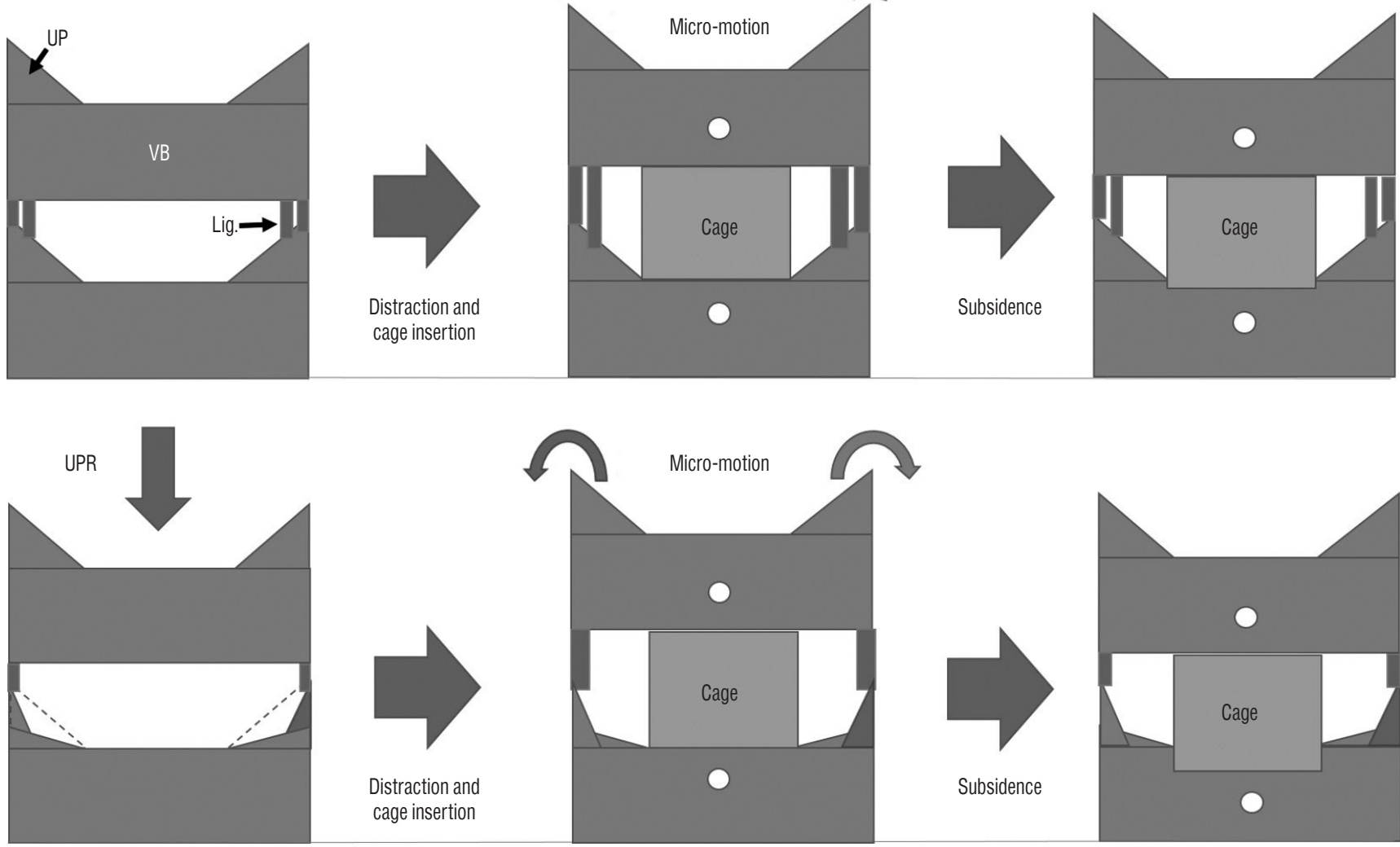

Fig. 1. Scheme illustrating the proposed relationship between uncinated process resection (UPR) and subsidence during anterior cervical discectomy and fusion (ACDF). The upper line demonstrates ACDF without UPR. Because of the intact uncovertebral joint, the segment achieves rigid stability. The lower line demonstrates ACDF with UPR. Through the disruption of bony structures and ligaments, UPR causes more micro-motion, which leads to the increase of subsidence. UP : uncinated process, VB : vertebral body, Lig. : ligaments surrounding uncovertebral joints. 
computed tomography (CT) scans, and 3) use of an allograft tissue cage and anterior plating. Thirty-eight patients ( 23 men) met the inclusion and exclusion criteria (Fig. 2). Mean age at surgery was $58.3 \pm 10.41$ years. Twenty-one patients underwent single-segment fusion, and 17 underwent two-segment fusion. No patients underwent $\mathrm{ACDF}$ at more than three levels. In total, 53 disc levels (C3-C4, 2; C4-C5, 7; C5-C6, 23; and C6C7, 23 but 2 excluded for inability to measure the lower C7 endplate) were investigated. The median follow-up duration was 18.5 months (range : 12.2-60.4 months).

\section{Surgical techniques}

All patients were operated on using the standard SmithRobinson anteromedial left-sided approach ${ }^{22}$. After removal of the intervertebral disc with a careful endplate preparation, a high-speed electric drill and Kerrison punch were used to decompress the nerve roots by removing osteophyte overgrowth on the uncovertebral joint and posterior lips of the vertebral body. We performed bilateral UP resection, even in patients with unilateral symptoms, to eliminate remnant osteophyte regrowth ${ }^{14)}$. UPR was advanced laterally until the nerve root was sufficiently decompressed. Adequate decompression was confirmed by the ability of a micro-hook to easily pass through the neural foramen. After decompression was complete, we determined the cage size, screw trajectory, and plate angle using fluoroscopy. An allograft tissue cage

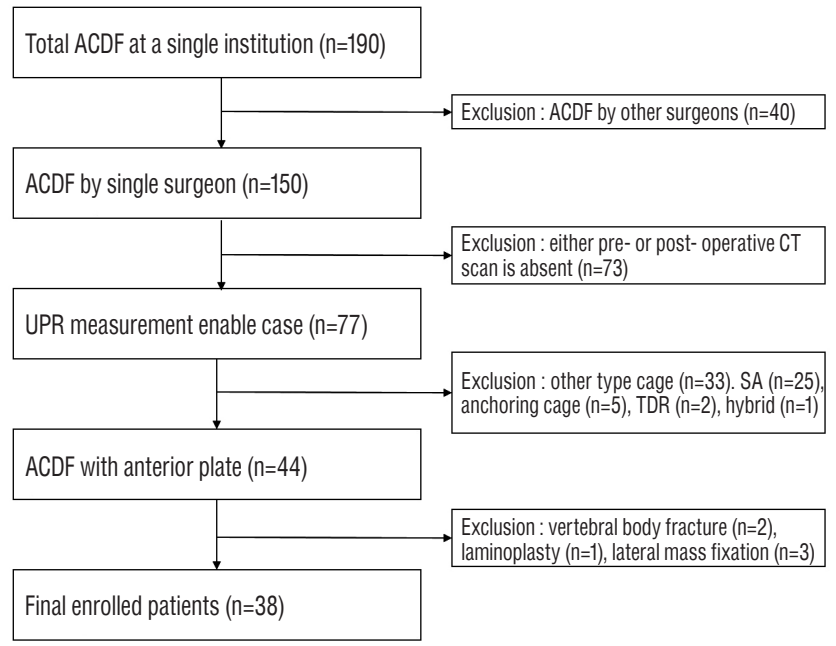

Fig. 2. Flow diagram depicting the patient inclusion process. ACDF : anterior cervical discectomy and fusion, CT : computed tomography, UPR : uncinated process resection area, SA : stand-alone cage, TDR : total disc replacement.
(Cornerstone ${ }^{\circledR}$-SR; Medtronic, Memphis, TN, USA) with an anterior plate (Zephir ${ }^{\circledR}$; Medtronic, Memphis, TN, USA) was applied under fluoroscopy. We tried to position the cage on the anterior edge of the upper vertebra to prevent subsidence ${ }^{1)}$. After release of the Caspar distractor, a manual pullout test confirmed the stability of the operation segments. All patients were instructed to wear a soft collar for 2 months after surgery.

\section{Radiological evaluation}

All radiological assessments were performed by two independent observers experienced in spinal diseases. Routine preoperative radiological work-up consisted of plain radiographs (standing anteroposterior [AP], lateral neutral, lateral flexion, lateral extension, and bilateral oblique views), CT, and magnetic resonance imaging. The total intervertebral height (TIH) was defined as the distance from the mid-point of the upper endplate of the cephalic vertebra to the closest point of the lower endplate of the caudal vertebra. Plain AP and lateral radiographs on postoperative day 7 were used to calculate $\mathrm{TIH}$ change when patients could stand. Subsidence was defined as a TIH decrease $\geq 3 \mathrm{~mm}$ into the adjacent vertebral body. The following possible risk factors for subsidence were considered : pre- and post- operative cervical angle and segmental angle, disc height, cage size, and cage distance from the anterior edge of the cranial vertebra (cage location) ${ }^{12,27)}$. Fusion status was defined as a lack of instability between the vertebral bodies on flexion and extension radiographs or the presence of bony bridging through the intervertebral space or around the cage. Pseudarthrosis was defined as segmental instability with $\geq 2 \mathrm{~mm}$ increase of interspinous distance or $\geq 2^{\circ}$ increase of segmental angle on flexion-extension lateral views at the most recent follow-up ${ }^{3)}$.

All subjects underwent CT pre-operatively and approximately 1 year postoperatively. Reformatted images (axial, coronal, and sagittal, all $2 \mathrm{~mm}$ thickness) were inverted to clearly reveal structural boundaries. Measurements were obtained from CT images using commercial software (Marosis 5.0; INFINITT Healthcare, Seoul, Korea). To calculate the bilateral UP and vertebral body (VB) areas, we obtained three sequential images moving anteriorly from the most posterior vertebral body (Fig. 3). To measure UP area, we first defined the UP base. When the bilateral pedicle silhouette was seen in the most posterior image, a line connecting the upper margin of 

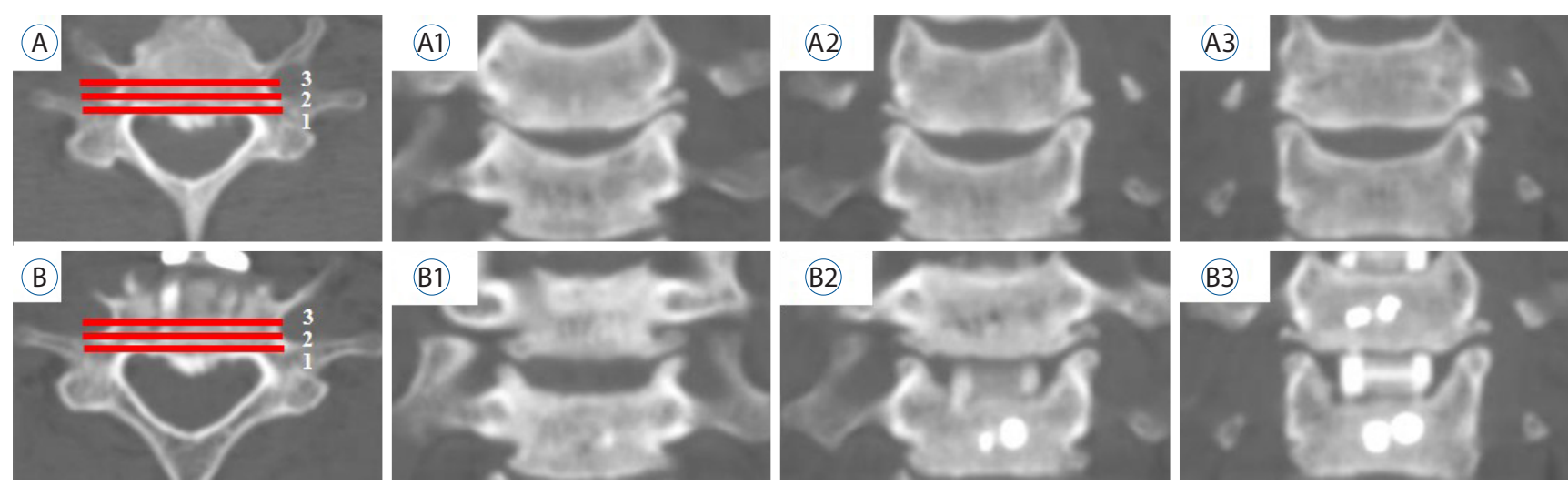

Fig. 3. Three sequential sections were obtained from the most posterior vertebral body toward the anterior direction. A : Pre-operative axial image at C6-7. B : postoperative axial image at the same level. A1-3 : Pre-operative coronal images. B1-3 : postoperative coronal images, with the number corresponding to the axial image (A and $B)$.
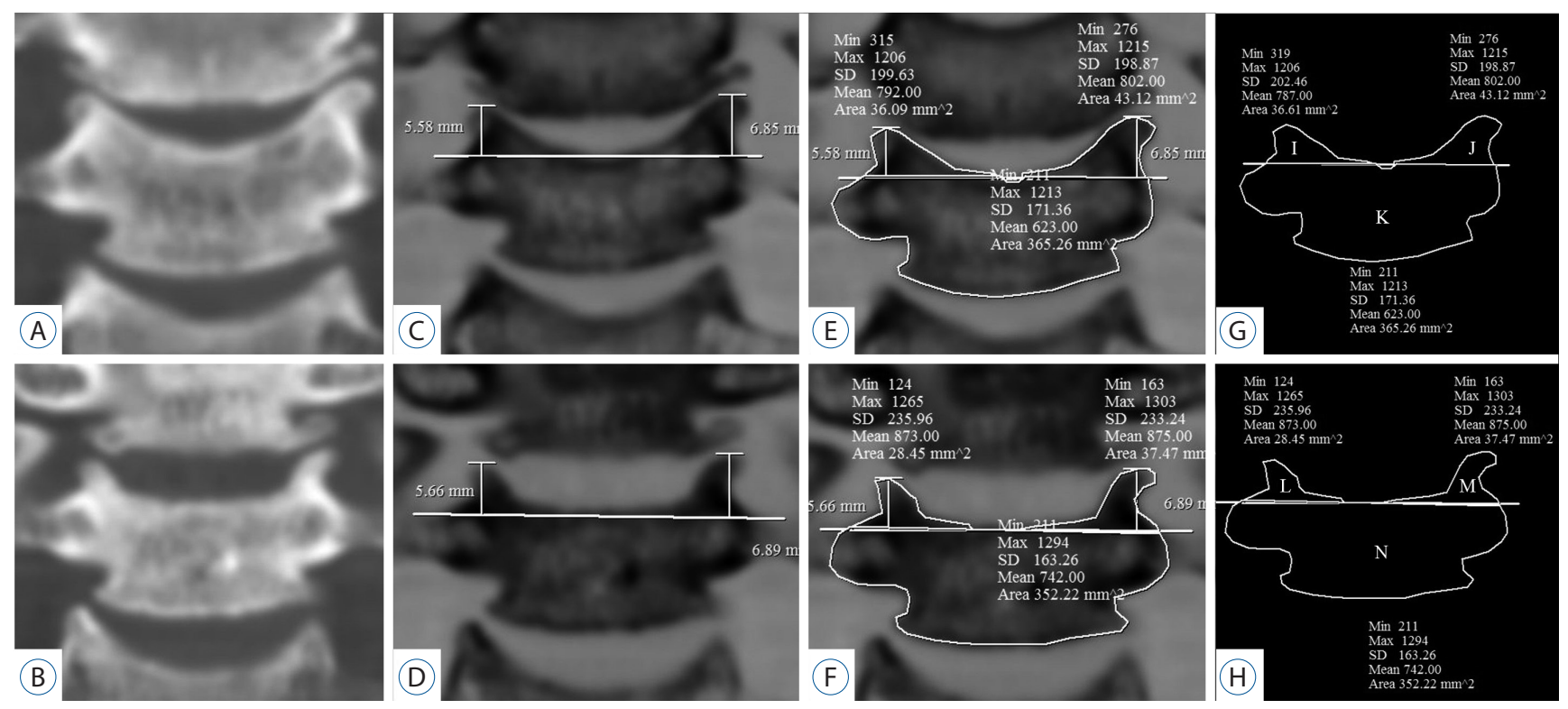

Fig. 4. Area measurements (uncinate process and vertebral body). A : Pre-operative (op), B : post-op coronal reformatted CT image at C5/6. C and D : The images are inverted. The base of the post-op UP was defined as a line connecting two points at the pre-op UP height. E and $F:$ Measurements of bilateral UPs and VB. G and H : Schema of the UP and VB. I=pre-op right (Rt.) UP, J=pre-op left (Lt.) UP, K=pre-op VB, L=post-op Rt. UP, M=post-op Rt. UP, $\mathrm{N}=$ post-op VB. Rt. pUPR=1-L/I, the difference in VB=K-N. CT : computed tomography, UP : uncinate process, VB : vertebral body, pUPR : proportion of UPR to pre-UP.

both pedicles was used as the UP base. If the pedicle was not visible in the most posterior image, the UP base was defined as parallel to the VB upper endplate. However, in the case of postoperative UPs, the upper endplate was disrupted due to intra-operative endplate preparation or postoperative subsidence. Therefore, to reliably identify the UP base postoperatively, we measured the shortest apex-to-base distance of the pre-operative UP, applied it to the postoperative image corresponding to the same coronal section, and defined postopera- tive UP base as a line connecting two points equidistant from the apex of the postoperative bilateral UPs (Fig. 4). The following areas were measured pre-operatively and postoperatively using commercial software : 1) the caudal VB except UPs and 2) bilateral UPs of the caudal VB. Because the UP and VB differ across cervical levels ${ }^{15)}$, we measured both UPR and the proportion of UPR (pUPR), defined as the ratio of UPR to pre-operative UP (Formula 1) (Fig. 4) : 
pUVR $=\frac{\sum_{1}^{3} U P R n}{\sum_{1}^{3} U P(\text { pre }) n}=\frac{\sum_{1}^{3}(U P(\text { pre }) n-U P(\text { post }) n)}{\sum_{1}^{3} U P(\text { pre }) n} \quad$ Formula 1

In formula $1, \mathrm{UP}$ (post) $\mathrm{n}=$ the postoperative area of the UP on coronal CT; UP(pre)n = the preoperative area of the UP on coronal CT. Based on these measurements, we calculated the 1) right UPR and pUPR, 2) left UPR and pUPR, 3) sum of bilateral UPR (sum UPR) and bilateral pUPR (sum pUPR), and 4) resected VB (VBR).

\section{Clinical evaluation}

Clinical evaluations summarized with the neck disability index (NDI) and the visual analog scale for neck pain (VAS-

Table 1. Pre-operative patient characteristics

\begin{tabular}{|c|c|c|c|}
\hline & Non-subsidence & Subsidence & $p$-value \\
\hline No. & 35 & 18 & \\
\hline $\operatorname{Sex}(M: F)$ & $24: 11$ & $13: 5$ & 0.784 \\
\hline Age (years) & $57.46 \pm 10.75$ & $59.39 \pm 8.71$ & 0.513 \\
\hline DM & $14 / 35$ & $8 / 18$ & 0.756 \\
\hline $\mathrm{BMI}\left(\mathrm{m}^{2} / \mathrm{kg}\right)$ & $24.94 \pm 3.62$ & $24.12 \pm 3.61$ & 0.439 \\
\hline Smoking & $15 / 35$ & $5 / 18$ & 0.283 \\
\hline Cage size & & & 0.082 \\
\hline 5 & 4 & 1 & \\
\hline 6 & 28 & 12 & \\
\hline 7 & 3 & 5 & \\
\hline Two-level fusion & $19 / 35$ & $10 / 18$ & 0.930 \\
\hline Operation level & & & 0.566 \\
\hline C3-4 & 2 & 0 & \\
\hline C4-5 & 4 & 3 & \\
\hline C5-6 & 16 & 7 & \\
\hline C6-7 & 13 & 8 & \\
\hline Uncoarthropathy & & & 0.226 \\
\hline None & 14 & 7 & \\
\hline HyperT & 15 & 3 & \\
\hline Fused & 6 & 8 & \\
\hline Facet degeneration & & & 0.836 \\
\hline None & 28 & 13 & \\
\hline HyperT & 3 & 5 & \\
\hline Fused & 4 & 0 & \\
\hline Follow-up (months) & $19.69 \pm 12.45$ & $16.25 \pm 4.86$ & 0.087 \\
\hline
\end{tabular}

neck), and arm pain (VAS-arm) were repeated at follow-up, and pre- and postoperative data were compared. At last follow-up, patients were also evaluated according to Odom's criteria, according to which, patients were rated from excellent to poor $^{16)}$.

\section{Statistical analysis}

The Shapiro-Wilk test was used to confirm normal distribution ( $p>0.05)$. Student's t-test and the Mann-Whitney U test for parametric and nonparametric continuous variables were used to compare radiologic and clinical outcomes between the subsidence (group S) and non-subsidence (group N), also fused and pseudarthrosis groups. Pearson's correlation analysis was used if just one of the parameters was normally distributed. Multiple linear regression analysis was performed by the stepwise method. In ROC analysis, the cut-off value was defined as the point of maximum sum of sensitivity and spec-

Table 2. Results of simple X-ray measurements

\begin{tabular}{|c|c|c|c|c|c|}
\hline & & & & Correlati & ion \\
\hline & subsidence & Subsidence & value & Coefficient & $\begin{array}{c}p- \\
\text { value }\end{array}$ \\
\hline Pre-operative & radiologic find & ding & & & \\
\hline $\mathrm{TIH}$ & $35.81 \pm 3.79$ & $35.49 \pm 3.09$ & 0.765 & -0.079 & 0.574 \\
\hline Disc height & $5.95 \pm 1.55$ & $5.78 \pm 1.95$ & 0.729 & -0.135 & 0.335 \\
\hline$C A$ & $8.48 \pm 10.01$ & $10.71 \pm 5.97$ & 0.451 & 0.218 & 0.117 \\
\hline SA & $3.05 \pm 3.79$ & $2.81 \pm 2.89$ & 0.838 & -0.063 & 0.652 \\
\hline ROM & $44.03 \pm 9.48$ & $43.06 \pm 12.03$ & 0.796 & -0.018 & 0.906 \\
\hline Intra-operati & e radiologic fin & ding & & & \\
\hline $\begin{array}{l}\text { Location of } \\
\text { cage }\end{array}$ & $1.67 \pm 1.21$ & $2.09 \pm 1.50$ & 0.107 & 0.148 & 0.290 \\
\hline $\mathrm{TIH}$ & $37.95 \pm 3.04$ & $37.24 \pm 3.03$ & 0.424 & -0.061 & 0.663 \\
\hline Disc height & $8.34 \pm 1.02$ & $8.66 \pm 0.91$ & 0.267 & 0.205 & 0.140 \\
\hline CA & $14.70 \pm 6.33$ & $14.36 \pm 5.46$ & 0.868 & 0.130 & 0.355 \\
\hline SA & $8.26 \pm 5.28$ & $8.79 \pm 5.94$ & 0.498 & -0.008 & 0.957 \\
\hline
\end{tabular}

Last follow-up radiologic finding

\begin{tabular}{lccccc} 
TIH & $35.96 \pm 3.13$ & $33.51 \pm 2.93$ & $0.008^{*}$ & -0.370 & $0.006^{*}$ \\
CA & $19.15 \pm 7.42$ & $18.44 \pm 8.85$ & 0.786 & 0.274 & 0.047 \\
SA & $8.67 \pm 6.34$ & $7.31 \pm 5.29$ & 0.498 & -0.084 & 0.552 \\
ROM & $33.61 \pm 9.22$ & $30.63 \pm 7.83$ & 0.365 & -0.098 & 0.487 \\
Pseudarthrosis & $5 / 35$ & $3 / 18$ & $>0.999$ & & \\
\hline
\end{tabular}

Normality of subsidence was tested using the Shapiro-Wilk test, $p=0.203$. *indicates statistical significance. $\mathrm{TIH}$ : total intervertebral height, CA : cervical angle, SA : segmental angle, ROM : range of motion 
ificity. $p<0.05$ were considered statistically significant. All analyses were performed using SPSS version 21 for Windows (SPSS Inc., Chicago, IL, USA).

\section{RESULTS}

\section{Patient characteristics}

In total, 38 patients (53 segments) were included in this study. Segments were divided into two groups : subsidence (group S; $\mathrm{n}=18$ ) and non-subsidence (group $\mathrm{N} ; \mathrm{n}=35$ ) (Table 1). No significant differences in age, sex, diabetes mellitus (DM) status, body mass index (BMI), or history of smoking were observed between the groups.

\section{Radiological outcomes}

Intraclass correlation coefficients (ICC[2,2]) for inter-observer agreement were 0.91 for UP area, 0.93 for VB area, 0.92 for UPR, and 0.81 for pUPR. TIH loss $>3 \mathrm{~mm}$ at the surgical level was observed in 18 segments (34\%). Psuedarthrosis occurred in eight patients (15.1\%) and there was no difference in pseudarthrosis incidence according to subsidence (Table 2).

No factors measured on sequential simple X-ray scan images or cervical alignment-associated factors (cervical angle, segmental angle, range of motion) significantly differed between groups $\mathrm{S}$ and $\mathrm{N}$ (Table 2). The factors measured on coronal CT images are summarized in Table 3.

Overall, UPR was similar bilaterally. However, left UPR was significantly higher in group $\mathrm{S}$ than in group N. In addition, the postoperative area of left UP, sum of UPR, sum of PUPR, left pUPR, and VBR were significantly higher in group $\mathrm{S}(\mathrm{Ta}-$ ble 3).

Using Pearson's correlation analysis, the postoperative left UP area, bilateral pUPR, VBR, and sum pUPR were significantly correlated with subsidence (Table 3). Multiple linear regression analysis was performed to remove confounding numerical factors. Although VBR was strongly correlated with

Table 3. Results of computed tomography measurements

\begin{tabular}{|c|c|c|c|c|c|c|c|}
\hline & \multirow{2}{*}{ Mean $\pm S D$} & \multirow{2}{*}{$p$-value } & \multicolumn{3}{|c|}{ Categorical comparison test for subsidence } & \multicolumn{2}{|c|}{$\begin{array}{l}\text { Bivariate Pearson's } \\
\text { correlation to subsidence }\end{array}$} \\
\hline & & & $\mathrm{TIH}<3 \mathrm{~mm}$ & $\mathrm{TIH} \geq 3 \mathrm{~mm}$ & $p$-value & Coefficient & $p$-value \\
\hline Pre-UP & & 0.409 & & & & & \\
\hline Right & $83.99 \pm 18.52$ & & $84.98 \pm 20.21$ & $82.05 \pm 15.04$ & 0.591 & -0.06 & 0.672 \\
\hline Left & $85.51 \pm 19.03$ & & $85.92 \pm 19.68$ & $84.70 \pm 18.22$ & 0.827 & -0.128 & 0.360 \\
\hline Post-UP & & 0.375 & & & & & \\
\hline Right & $50.88 \pm 18.27$ & & $53.25 \pm 20.31$ & $46.28 \pm 12.71$ & $0.132^{\dagger}$ & -0.244 & 0.079 \\
\hline Left & $52.80 \pm 19.33$ & & $57.11 \pm 21.15$ & $44.43 \pm 11.64$ & $0.007^{* \dagger}$ & -0.306 & $0.026^{*}$ \\
\hline UPR & & 0.872 & & & & & \\
\hline Right & $33.10 \pm 13.75$ & & $31.73 \pm 15.77$ & $35.77 \pm 8.31$ & $0.227^{\dagger}$ & 0.244 & 0.079 \\
\hline Left & $32.70 \pm 17.33$ & & $28.81 \pm 17.31$ & $40.27 \pm 15.08$ & $0.021^{*}$ & 0.201 & 0.149 \\
\hline pUPR & & 0.557 & & & & & \\
\hline Right & $0.40 \pm 0.17$ & & $0.38 \pm 0.19$ & $0.44 \pm 0.09$ & $0.096^{\dagger}$ & 0.310 & $0.024^{*}$ \\
\hline Left & $0.39 \pm 0.17$ & & $0.34 \pm 0.18$ & $0.47 \pm 0.12$ & $0.002^{*+\dagger}$ & .0301 & $0.029^{*}$ \\
\hline Pre-VB & $1178.36 \pm 181.65$ & & $1162.28 \pm 183.73$ & $1209.63 \pm 178.47$ & 0.374 & 0.107 & 0.446 \\
\hline Post-VB & $1126.60 \pm 151.94$ & & $1137.76 \pm 164.14$ & $1104.90 \pm 126.40$ & 0.461 & -0.100 & 0.477 \\
\hline VB resection area & $51.76 \pm 95.71$ & & $24.52 \pm 66.16$ & $104.73 \pm 121.52$ & $0.003^{*}$ & 0.362 & $0.008^{*}$ \\
\hline Sum of bilateral UPR & $65.81 \pm 25.62$ & & $60.55 \pm 26.99$ & $76.04 \pm 19.56$ & $0.036^{*}$ & 0.267 & 0.054 \\
\hline Sum of bilateral pUPR ${ }^{\ddagger}$ & $0.39 \pm 0.14$ & & $0.36 \pm 0.15$ & $0.46 \pm 0.07$ & $0.004^{*^{+}}$ & 0.364 & $0.007^{*}$ \\
\hline
\end{tabular}

*Indicates statistical significance, ${ }^{\dagger}$ Levine's test for equality of variances $<0.05,{ }^{\ddagger}$ Sum of bilateral pUPR $=(\mathrm{UPR}$ right+UPR left)/(pre-UP right+pre-UP left). SD : standard deviation, Pre-UP : pre-operative area of the uncinated process (UP), Post-UP: postoperative area of the UP, UPR : the area of UP resection, PUPR : proportion of UPR to pre-UP, VB : vertebral body 
subsidence, it was not included in multiple linear regression analysis because they reflect the same phenomenon and are not independent. Furthermore, partial correlation analysis demonstrated a statistically significant correlation between pUPR and subsidence in the absence of the influence of VBR (VBR controlled, $\mathrm{r}=0.301, p=0.03$ ). According to stepwise selection, only sum pUPR had statistical significance $(p=0.007$; $\mathrm{R}^{2}=0.133$; adjusted $\mathrm{R}^{2}=0.116$ ) according to the following formula (Formula 2) : subsidence=1.522+2.7×sum pUPR (Fig. 5).

Receiver operating characteristic (ROC) analysis was performed to determine the cut-off value of sum pUPR that induced significant subsidence (Fig. 6), indicating that sum $p U P R \geq 0.38$ could serve as a threshold for significantly increased risk of subsidence $(p=0.005$, area under curve $=0.737$, sensitivity $=94 \%$, specificity $=51 \%$ ). Using this value, we converted sum $\mathrm{pUPR}$ into a bifurcated variable (sum $\mathrm{pUPR}<0.38$, sum $\mathrm{PUPR} \geq 0.38$ ) and performed logistic regression analysis, which revealed that this threshold value was significantly associated with subsidence $(p=0.009$, odds ratio $=8.471,95 \%$ confidence interval=1.689-42.483).

\section{Clinical outcomes}

The mean values of VAS-neck, VAS-arm, and NDI are summarized in Table 4 . The scores decreased significantly at the final follow-up $(p<0.01)$. Despite significant subsidence, the result of Odom's criteria and the mean improvements of VAS, NDI in group S were not different from group N.

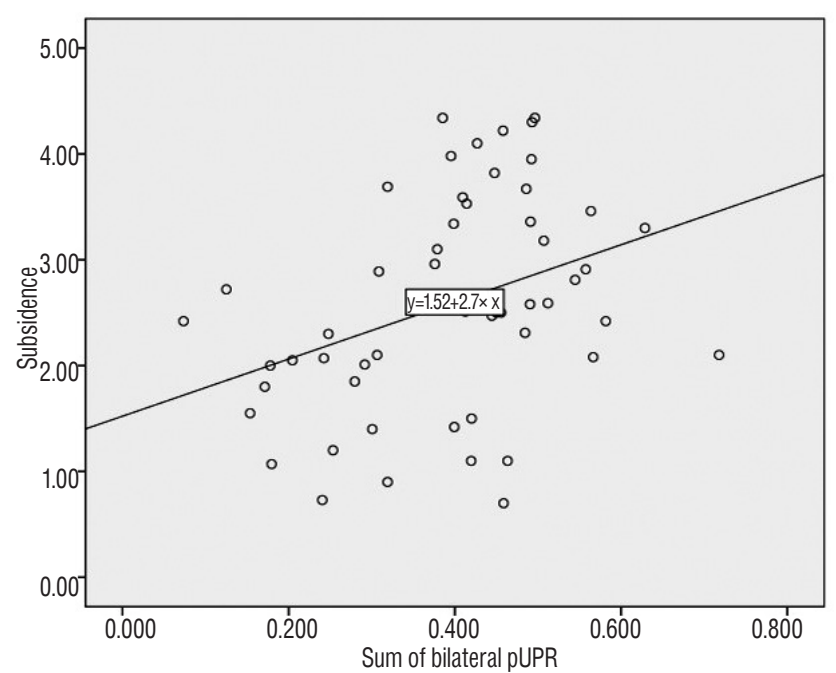

Fig. 5. Simple scatter graph and regression analysis between subsidence and the sum of bilateral pUPR $\left(p=0.007 ; R^{2}=0.133 ;\right.$ adjusted $\left.R^{2}=0.116\right)$. pUPR : proportion of uncinate process resection to pre-uncinate process area.

\section{DISCUSSION}

Subsidence is a major complication of ACDF, which can result in foramen narrowing, nerve root compression, pseudarthrosis due to cervical instability, and adjacent segment degeneration due to loss of lordosis ${ }^{27)}$. In this study, the influence of intra-operative factors such as intraoperative distraction ${ }^{6}$, endplate preparation ${ }^{13)}$, and cage position ${ }^{1)}$ on subsidence was reduced because all included cases were operated on by a single surgeon. However, patient factors such as DM, BMI, smoking, and cervical alignment were not controlled, potentially limited the observed correlation strength between PUPR and subsidence ( $\mathrm{r}=0.364$; moderate positive correlation).

Micro-motion has been reported to cause subsidence ${ }^{9,17,26)}$, leading us to question whether such micro-motion increased with UPR. Since micro-motion cannot be estimated directly, we used subsidence as a proxy. ACDFP provides stronger fixation than stand-alone cages and is affected only by small external forces such as lateral tilting, axial rotation, and coupling rather than by large external forces such as flexion/extension. These small external forces are consistent with the main limi-

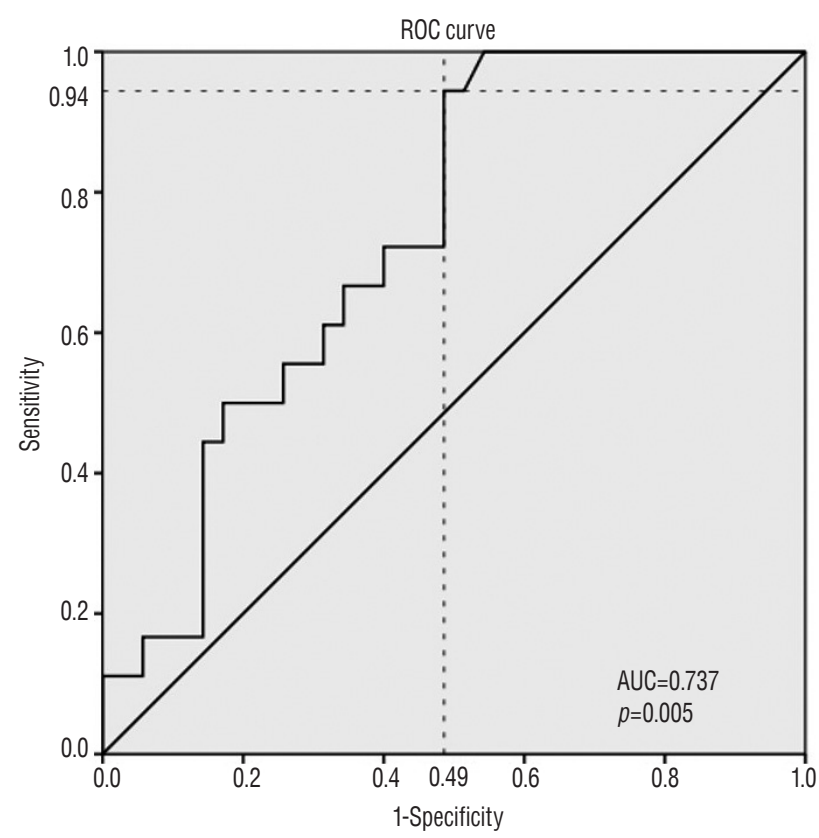

Fig. 6. Receiver operating characteristic (ROC) analysis was performed to determine the cut-off value of sum pUPR that induced significant subsidence. Sum pUPR above 0.38 could serve as a threshold for significantly increased risk of subsidence ( $p=0.005, A U C=0.737$, sensitivity $=94 \%$, specificity $=51 \%)$. pUPR : proportion of uncinate process resection (UPR) to pre-uncinate process (UP) area. 
Table 4. Clinical outcomes

\begin{tabular}{lcccc}
\hline & All $(\mathbf{n}=53)$ & $\begin{array}{c}\text { Non- } \\
\text { subsidence } \\
(\mathbf{n}=\mathbf{3 5})\end{array}$ & $\begin{array}{c}\text { Subsidence } \\
(\mathbf{n}=\mathbf{1 8})\end{array}$ & $\boldsymbol{p}$-value \\
\hline VAS-neck & & & & \\
Pre-op & $5.02 \pm 1.28$ & $4.94 \pm 1.28$ & $5.17 \pm 1.29$ & 0.551 \\
Post-op & $2.58 \pm 1.01$ & $2.43 \pm 0.98$ & $2.89 \pm 1.02$ & 0.116 \\
Improvement & $2.43 \pm 1.32$ & $2.51 \pm 1.42$ & $2.28 \pm 1.13$ & 0.543 \\
VAS-arm & & & & \\
Pre-op & $6.62 \pm 1.11$ & $6.66 \pm 1.19$ & $6.56 \pm 0.98$ & 0.756 \\
Post-op & $2.40 \pm 1.15$ & $2.40 \pm 1.14$ & $2.39 \pm 1.20$ & 0.974 \\
Improvement & $1.23 \pm 1.41$ & $4.26 \pm 1.52$ & $4.17 \pm 1.20$ & 0.827 \\
NDI & & & & \\
Pre-op & $53.45 \pm 12.62$ & $53.97 \pm 12.42$ & $52.44 \pm 13.31$ & 0.681 \\
Post-op & $24.62 \pm 11.48$ & $24.94 \pm 11.53$ & $24.00 \pm 11.67$ & 0.780 \\
Improvement & $28.83 \pm 10.42$ & $29.03 \pm 10.91$ & $28.44 \pm 9.69$ & 0.849 \\
\hline Odom's criteria & & & & \\
Excellent & $6(11.3)$ & 0 & 6 & 0.310 \\
Good & $33(62.3)$ & 12 & 21 & \\
Fair & $12(22.6)$ & 6 & 6 & \\
Poor & $2(3.8)$ & 0 & 2 & \\
\hline
\end{tabular}

Values are presented as mean \pm standard deviation or number (\%). VASneck : visual analog scale for neck pain, Pre-op : pre-operative, Post-op : post-operative, VAS-arm : VAS for arm pain, NDI : neck disability index

tation mechanism of UPs ${ }^{4,11,25)}$. Compared with ACDFP, the flexion/extension force caused by annulotomy and discectomy is insufficiently supported in ACDF with stand-alone cage ${ }^{4)}$, thus attenuating the effects of small external forces. To demonstrate this connection, we analyzed the 11 patients (17 levels) who underwent ACDF using stand-alone polyether-ether-ketone (PEEK) cage data from Pusan National University Yangsan Hospital, found no correlation between subsidence and pUPR, and observed excessive subsidence compared to the subsidence calculated by formula 2 (Fig. 7). These results indicate that the subsidence of ACDF with stand-alone cage is not representative of the small external forces that depend on UPR.

Since the most posterior one-third of the UP provides the majority of the limitation mechanism of the uncovertebral joint $^{11)}$, we measured the three most posterior coronal images from the VB. Furthermore, we calculated the sum of the three image areas to reduce alignment bias, because the change in cervical alignment after ACDF makes it impossible to obtain the same images for all patients during postoperative CT

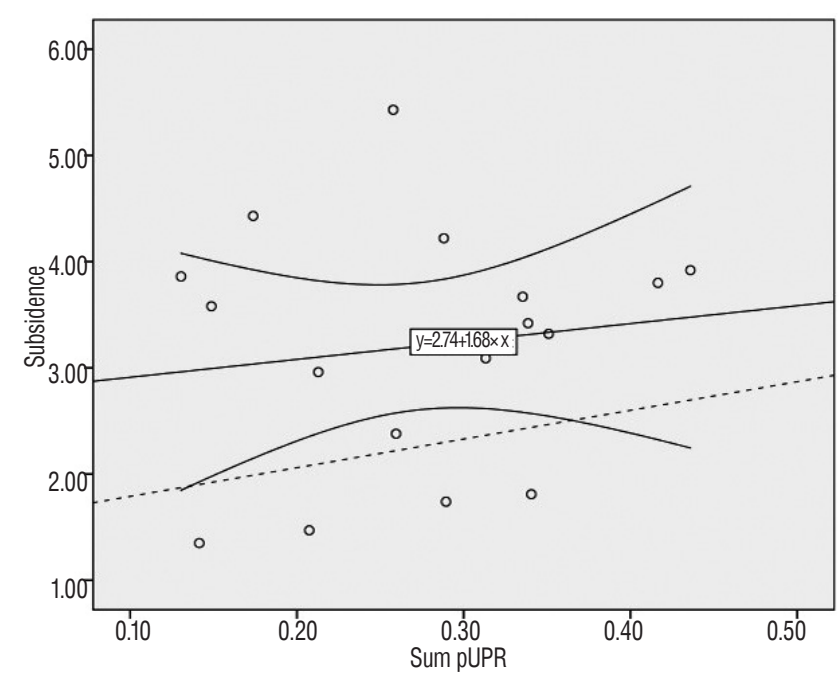

Fig. 7. Simple scatter plot: linear regression line with $95 \%$ confidence interval between subsidence and the sum of bilateral pUPR in ACDF with stand-alone PEEK cage $(R=0.139, p=0.595)$. The dashed line represents the expected subsidence calculated by formula 2 : subsidence $=1.522+2.7 \times$ sum pUPR. pUPR : proportion of uncinate process resection to preuncinate process area, ACDF : anterior cervical discectomy and fusion, PEEK : polyether-ether-ketone.

scanning.

A challenge of the method for UP area measurement described here is determining the base of the postoperative UP, because the endplate is disrupted by preparation and subsidence. Since there were no cases in which the surgeon damaged the UP apex, we estimated the postoperative UP base by using the apex of the postoperative UP as a reference point. The ICC $(2,2)$ of the UP area measurement, 0.91 , indicated satisfactory agreement. Subsidence is closely related to the reduction of the upper endplate area. However, since base-line estimation is an imperfect method, the area of the upper end-plate risks being included in pre- and postoperative UP area measurements. In this event, the observed relation of UPR to subsidence may stem from the unintended inclusion of the upper endplate. Partial correlation analysis was conducted to eliminate this possibility. The upper endplate should theoretically be included in the VB, but after excluding the influence of VB, the UPR association with subsidence remained strong. Thus, the correlation of UPR and subsidence is not related to the upper endplate.

A PubMed search with the key words "uncinate process", "uncovertebral joint", "resection", and "decompression" revealed one previous study ${ }^{21)}$ on the effect of UPR in vivo, which focused on post-resection fusion rate and clinical out- 
comes. Its authors noted that uncovertebral joint preservation would provide the optimal environment for successful fusion if equivalent functional outcomes were assumed, but could not provide a reliable threshold at which UPR begins to cause subsidence. Our findings support this perspective, and by quantitative analysis of UPR, we were further able to determine a value that allowed a suitable operative view without negatively affecting postoperative stability.

Contrary to our expectation, resection was greater on the side of surgical approach (Table 3), suggesting that adequate resection was possible on the right side with sufficient visual field, but could be excessive on the left side, with a limited field of view.

This study had several limitations. Because it was retrospective and included patients who underwent follow-up CT, selection bias may have influenced the observed rate of subsidence (34\%), which is higher than that reported previously $(9.7 \%)^{23)}$. However, other studies without such selection bias reported similar subsidence rates : $30 \%{ }^{8)}$ and $33 \%{ }^{19)}$. To reduce selection bias, a prospective study is needed in which all patients undergo CT scanning. Second, we used estimated baselines for postoperative UP. To reduce measurement bias, the CT scans were performed immediately postoperatively. However, repeating CT scans over short periods is unrealistic. Third, we performed bilateral partial UP resection on all segments; there were no cases of intact UP or total resection. The lack of such data is a limitation to accurate ROC analysis. Finally, this study was a small-sized, relatively short-term study that could not prove differences in clinical outcome, fusion, and cervical alignment according to subsidence. The impact of subsidence on these factors is still controversial, but there is a report that subsidence is associated with poor clinical outcome in long-term follow-up ${ }^{10)}$. In this regard, we need to pay attention to minimize subsidence and we need a large-scale, long-term study to clarify it.

\section{CONCLUSION}

We have devised a measurement method to calculate UPR. Our findings suggest that if the sum of pUPR is $\geq 38 \%$, the possibility of subsidence increases significantly. Furthermore, we should use caution to avoid excessive UPR on the side of surgical approach.

\section{- Acknowledgements}

This study was supported by Research institute for Convergence of biomedical science and technology (30-2016-011), Pusan National University Yangsan Hospital.

\section{References}

1. Barsa P, Suchomel P : Factors affecting sagittal malalignment due to cage subsidence in standalone cage assisted anterior cervical fusion. Eur Spine J 16 : 1395-1400, 2007

2. Bartels $R H$, Donk RD, Feuth $T$ : Subsidence of stand-alone cervical carbon fiber cages. Neurosurgery 58 : 502-508; discussion 502-508, 2006

3. Cannada LK, Scherping SC, Yoo JU, Jones PK, Emery SE : Pseudoarthrosis of the cervical spine: a comparison of radiographic diagnostic measures. Spine (Phila Pa 1976) 28 : 46-51, 2003

4. Chen TY, Crawford NR, Sonntag VK, Dickman CA : Biomechanical effects of progressive anterior cervical decompression. Spine (Phila Pa 1976) $26: 6$-13; discussion 14, 2001

5. Ebraheim NA, Lu J, Haman SP, Yeasting RA : Anatomic basis of the anterior surgery on the cervical spine: relationships between uncus-arteryroot complex and vertebral artery injury. Surg Radiol Anat 20 : 389392, 1998

6. Francke El, Demetropoulos CK, Agabegi SS, Truumees E, Herkowitz HN Distractive force relative to initial graft compression in an in vivo anterior cervical discectomy and fusion model. Spine (Phila Pa 1976) 35 526-530, 2010

7. Gercek E, Arlet V, Delisle J, Marchesi D : Subsidence of stand-alone cervical cages in anterior interbody fusion: warning. Eur Spine J 12 : 513 516, 2003

8. Joo YH, Lee JW, Kwon KY, Rhee JJ, Lee HK : Comparison of fusion with cage alone and plate instrumentation in two-level cervical degenerative disease. J Korean Neurosurg Soc 48 : 342-346, 2010

9. Kettler $A$, Wilke HJ, Claes $L$ : Effects of neck movements on stability and subsidence in cervical interbody fusion: an in vitro study. J Neurosurg 94(1 Suppl) : 97-107, 2001

10. Kim WB, Hyun SJ, Choi H, Kim KJ, Jahng TA, Kim HJ : Long-term followup results of anterior cervical inter-body fusion with stand-alone cages.

J Korean Neurosurg Soc 59 : 385-391, 2016

11. Kotani Y, McNulty PS, Abumi K, Cunningham BW, Kaneda K, McAfee $P C$ : The role of anteromedial foraminotomy and the uncovertebral joints in the stability of the cervical spine. A biomechanical study. Spine (Phila Pa 1976) 23 : 1559-1565, 1998

12. Lee YS, Kim YB, Park SW : Risk factors for postoperative subsidence of single-level anterior cervical discectomy and fusion: The significance of the preoperative cervical alignment. Spine (Phila Pa 1976) 39 : 1280 1287, 2014

13. Lim $T H$, Kwon $H$, Jeon $C H$, Kim JG, Sokolowski M, Natarajan $R$, et al. : Effect of endplate conditions and bone mineral density on the compres 
Uncinated Process Resection and Subsidence | Lee SH, et al.

sive strength of the graft-endplate interface in anterior cervical spine fusion. Spine (Phila Pa 1976) 26 : 951-956, 2001

14. Liu Y, Luo X, Zhou J, Li N, Peng S, Rong P, et al. : Prognosis of posterior osteophyte after anterior cervical decompression and fusion in patients with cervical spondylotic myelopathy using three-dimensional computed tomography study. Eur Spine J 25 : 1861-1868, 2016

15. Milne $\mathrm{N}$ : The role of zygapophysial joint orientation and uncinate processes in controlling motion in the cervical spine. J Anat 178 : 189-201, 1991

16. Odom GL, Finney W, Woodhall B : Cervical disk lesions. J Am Med Assoc $166: 23-28,1958$

17. Olivares-Navarrete R, Gittens RA, Schneider JM, Hyzy SL, Haithcock $\mathrm{DA}, \mathrm{Ulll}$ rich $\mathrm{PF}$, et al. : Osteoblasts exhibit a more differentiated phenotype and increased bone morphogenetic protein production on titanium alloy substrates than on poly-ether-ether-ketone. Spine J 12 : 265-272, 2012

18. Park JY, Choi KY, Moon BJ, Hur H, Jang JW, Lee JK : Subsidence after single-level anterior cervical fusion with a stand-alone cage. J Clin Neurosci $33: 83-88,2016$

19. Pinder EM, Sharp DJ : Cage subsidence after anterior cervical discectomy and fusion using a cage alone or combined with anterior plate fixation. J Orthop Surg (Hong Kong) 24 : 97-100, 2016

20. Schmieder K, Wolzik-Grossmann M, Pechlivanis I, Engelhardt M, Scholz $M$, Harders A : Subsidence of the wing titanium cage after anterior cervical interbody fusion: 2-year follow-up study. J Neurosurg Spine 4 : 447-453, 2006
21. Shen FH, Samartzis D, Khanna N, Goldberg EJ, An HS : Comparison of clinical and radiographic outcome in instrumented anterior cervical discectomy and fusion with or without direct uncovertebral joint decompression. Spine J 4 : 629-635, 2004

22. Smith GW, Robinson RA : The treatment of certain cervical-spine disorders by anterior removal of the intervertebral disc and interbody fusion. J Bone Joint Surg Am 40-A : 607-624, 1958

23. Song KJ, Taghavi CE, Lee KB, Song JH, Eun JP : The efficacy of plate construct augmentation versus cage alone in anterior cervical fusion. Spine (Phila Pa 1976) 34 : 2886-2892, 2009

24. Tanaka N, Fujimoto Y, An HS, Ikuta Y, Yasuda M : The anatomic relation among the nerve roots, intervertebral foramina, and intervertebral discs of the cervical spine. Spine (Phila Pa 1976) 25 : 286-291, 2000

25. White AA, Panjabi MM : Clinical biomechanics of the spine, ed 2. Philadelphia: Lippincott, 1990

26. Wu SH, Li Y, Zhang YQ, Li XK, Yuan CF, Hao YL, et al. : Porous titanium- 6 aluminum- 4 vanadium cage has better osseointegration and less micromotion than a poly-ether-ether-ketone cage in sheep vertebral fusion. Artif Organs 37 : E191-E201, 2013

27. Yang JJ, Yu CH, Chang BS, Yeom JS, Lee JH, Lee CK : Subsidence and nonunion after anterior cervical interbody fusion using a stand-alone polyetheretherketone (peek) cage. Clin Orthop Surg 3 : 16-23, 2011

28. Yao R, McLachlin SD, Rasoulinejad P, Gurr KR, Siddiqi F, Dunning $C E$, et al. : Influence of graft size on spinal instability with anterior cervical plate fixation following in vitro flexion-distraction injuries. Spine J 16 : 523-529, 2016 